\title{
Rapid quantification of highly polar trimethyl phosphate in wastewater via direct analysis in real-time mass spectrometry
}

\author{
Xiaowei Wang ${ }^{\mathrm{a}}$, Jingfu Liu ${ }^{\mathrm{b}}$, Charles C. Liu ${ }^{\mathrm{c}}$, Jing Zhang ${ }^{\mathrm{a}}$, Bing Shao ${ }^{\mathrm{a}, *}$, Liping Liu ${ }^{\mathrm{a}}$, \\ Nina Zhang ${ }^{\mathrm{a}}$ \\ a Beijing Key Laboratory of Diagnostic and Traceability Technologies for Food Poisoning, Beijing Centers for Diseases Control and Prevention E' Centers for \\ Preventive Medical Research, Beijing 100013, China \\ b State Key Laboratory of Environmental Chemistry and Ecotoxicology, Research Center for Eco-environmental Sciences, Chinese Academy of Sciences, \\ P.O. Box 2871, Beijing 100085, China \\ c ASPEC Technologies Limited, Beijing 100102, China
}

\section{A R T I C L E I N F O}

\section{Article history:}

Received 29 October 2013

Received in revised form

30 December 2013

Accepted 27 January 2014

Available online 3 February 2014

\section{Keywords:}

Organophosphorus flame retardant

Trimethyl phosphate

Direct analysis real-time tandem mass

spectrometry

Environmental water

\begin{abstract}
A B S T R A C T
Trimethyl phosphate (TMP) is used extensively in industrial chemical processes. Due to the high polarity and volatility, methods for its quantification in environmental samples have not been well developed. Currently, the pollution status of TMP in the environment still has not been quantitatively analyzed. This study quantifies the TMP levels in environmental water via direct analysis real-time ionization source interfaced with a triple quadrupole mass spectrometer (DART-MS/MS) with multiple reaction monitoring (MRM). The DART parameters were optimized to achieve the most TMP-sensitive MRM responses. The water samples were analyzed directly, and an isotope-labeled internal standard (ISTD) method was applied for quantification. The method exhibits significant linearity $(R>0.998)$ in the range of $0.05-100 \mathrm{ng} / \mathrm{mL}$, with a limit of quantification (LOQ) of $50 \mathrm{pg} / \mathrm{mL}$. TMP has been accurately detected in the influent and effluent water of two municipal wastewater treatment plants and a river located in Beijing. Recovery of TMP ranged $88.0-107.6 \%$ for the spiked real water samples. The results demonstrated that TMP has been existed in environmental water, and DART-MS/MS can be used for the monitoring of the pollution status and the environmental process of TMP in environmental water.
\end{abstract}

(c) 2014 Elsevier B.V. All rights reserved.

\section{Introduction}

Organophosphate esters (OPEs) have recently found wide use as flame retardants, plasticizers, and antifoaming agents [1,2]. Among the OPEs, trimethyl phosphate (TMP) shows the highest polar and volatile [3], and has been widely used as a solvent and methylating agent, a color inhibitor, and an intermediate or catalyst for various industrial chemical processes [4,5]. In addition, TMP has been extensively studied as a stimulant in organophosphate nerve gas warfare agents [6].

TMP is believed persistence in nature [7]. The extensive use of TMP causes its release into the environment, and uptake by organisms. The median lethal dose $\left(\mathrm{LD}_{50}\right)$ value of TMP was reported as $840 \mathrm{mg} / \mathrm{kg}$, and TMP has proven to be genotoxic [1,3]. Low dose and repeated exposure to TMP caused a significant decrease in body weight, a substantial change in hematology, increased kidney damage, and heritable genetic damage to human germ cells $[8,9]$. Therefore, understanding the pollution status, environmental

\footnotetext{
* Corresponding author. Tel.: +8610 64407191; fax: +861064407191.

E-mail address: shaobingch@sina.com (B. Shao).
}

process of TMP is critical. Many studies have been carried on for OPEs. The data for TMP, however, have been limited mainly due to a lack of proper analytical methodologies.

Conventional approaches for analyzing OPEs have primarily utilized liquid-liquid extraction (LLE) or solid-phase extraction (SPE) coupled with gas chromatography-mass spectrometry (GC-MS) [10-12] or liquid chromatography-tandem mass spectrometry (LC-MS/MS) $[2,13]$. Due to its high polarity $\left(\log K_{\text {ow }}=-0.65\right)$ and volatility (vapor pressure $=0.74 \mathrm{~Pa}\left(25^{\circ} \mathrm{C}\right)$ ) [3], the recovery of TMP via LLE or SPE has been too low for quantification $[2,10,12,14,15]$.

As an ambient ionization technique, direct analysis in real-time (DART) ion source ionizes a sample and introduces the ions into the mass spectrometer with minimal or no sample preparation. Since its inception [16], DART has been successfully applied in many fields [17-21]. Most importantly, the reliability and reproducibility of the DART has been improved in recent years allowing its use as a quantification tool $[22,23]$. Compared with its application in the field of food and drug analysis, the use of DART in environmental science is relatively new [20].

This study aims to develop a highly sensitive, rapid, accurate, and reproducible method for the quantitative analysis of TMP in environmental water via DART-MS/MS without a tedious 
pretreatment process. The various advantages of multiple reaction monitoring (MRM) and DART were exploited. Without requiring sample pretreatment and chromatographic separation, the analysis process can be completed in seconds. Furthermore, the use of a commercially available isotope-labeled TMP as an internal standard enhanced the accuracy. With this approach, the TMP levels in environment water have been accurately and precisely determined for the first time.

\section{Experimental}

\subsection{Reagents and materials}

TMP was purchased from Dr. Ehrenstorfer GmbH (Augsburg, Germany). Isotope-labeled TMP (trimethyl- $d_{9}$-phosphate, TMP- $d_{9}$ ) was obtained from C/D/N ISOTOPES INC. (Pointe-Claire, Quebec, Canada). Methanol (MeOH, optima grade) was purchased from Fisher Scientific (Waltham, MA, USA). Ultra-pure water (18.3 M $\Omega$ ) produced with a Milli-Q gradient system (Millipore, Bedford, USA), was used throughout the experiments.

Individual stock TMP and TMP-d s $_{9}$ solutions $(1.00 \mathrm{mg} / \mathrm{mL})$ were prepared by dissolving the reference materials in $\mathrm{MeOH}$. A $10.0 \mu \mathrm{g} / \mathrm{mL}$ TMP working solution and $1.00 \mu \mathrm{g} / \mathrm{mL} \mathrm{TMP-d}_{9}$ internal standard solution (ISs) were prepared by diluting the stock solutions with $\mathrm{MeOH}$. Ten standard solutions $(0.05-100 \mathrm{ng} / \mathrm{mL})$ were diluted into $1.00 \mathrm{~mL}$ ultra-pure water. A $20 \mu \mathrm{L}$ ISs was added to each standard solution and the final concentration of TMP- $\mathrm{d}_{9}$ was close to $20 \mathrm{ng} / \mathrm{mL}$. Each standard solution was analyzed five times in parallel. All stock solutions were maintained in $4{ }^{\circ} \mathrm{C}$.

\subsection{Sample collection and pretreatment}

Influent and effluent wastewater samples were collected from two municipal wastewater treatment plants (WWTPs) in Beijing, China. One WWTP was located in east (W-1-inf, W-1-eff) Beijing and the other in the southwest (W-2-inf, $\mathrm{W}$-2-eff). A river water sample was collected from a river which received the effluent water of $\mathrm{W}-1$, and the sampling site was located in the downstream of $\mathrm{W}-1$ 's outfall. The water samples were preserved at $4{ }^{\circ} \mathrm{C}$. Before analysis, each sample was mixed with a vortex for $1 \mathrm{~min}$. Water sample $(1.00 \mathrm{~mL})$ was weighed and added a $20.0 \mu \mathrm{L}$ ISs to ensure the final concentration of TMP-d9 in each water sample was same as the concentration in standard solution. Then filtered through a $0.45 \mu \mathrm{m}$ cellulose acetate membrane (Sartorius, Germany). Spiked water samples were treated using the same method. Each sample was measured for five times in parallel.

\subsection{DART-MS/MS analysis}

A DART SVP ionization source (IonSense, Saugus, MA, USA, supplied by ASPEC Technologies Limited, Beijing, China) connected to a Xevo TQ-S triple quadrupole mass spectrometer (Waters, Milford, MA, USA) through a VAPUR interface (IonSense, Saugus, MA, USA) was employed in this study. High-purity nitrogen and helium (99.995\%) were used.

The DART SVP and the mass spectrometer were all operated in the positive ion mode, but controlled separately using their individual control software interfaces. The DART SVP was installed according to the manufacturer's instructions, and ran in free-run mode. The orifice of the DART ion source and the ceramic ion transfer tube were separated by $8 \mathrm{~mm}$ for this study. 12-DIP-it sampler (IonSense, Saugus, MA, USA) introduced the samples into the mass spectrometer (Fig. 1). The sample sticks were immersed for $1 \mathrm{~s}$ in glass vials containing water samples and were allowed to dry for $10 \mathrm{~s}$ until no liquid was observed. The drying time was included because large liquid droplets on the tips of the sticks could be blown into mass spectrometer by the helium, thus negatively affecting

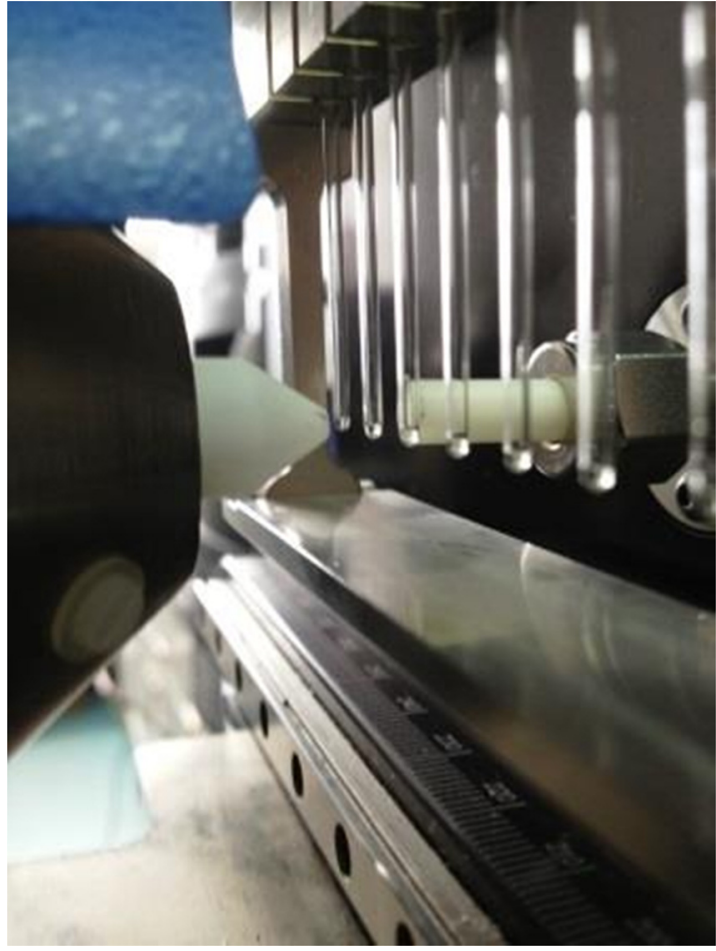

Fig. 1. Photograph of the DART-MS/MS injection process.

the reproducibility of the analysis. After drying, the sample sticks were passed through the gap between the DART ion source and the ceramic ion sampling tube at a steady rate.

The quantitative MRM transitions of TMP and TMP-d9 protonated ions, $[\mathrm{M}+\mathrm{H}]^{+}$, were $m / z 140.97>108.95$ and $150.11>114.97$, and their collision energies (Ecoll) were $16 \mathrm{eV}$ and $18 \mathrm{eV}$, respectively. The qualitative MRM transition ions were $m / z 140.97>78.93$, Ecoll $20 \mathrm{eV}$ for TMP and $m / z 150.11>82.99$, Ecoll $21 \mathrm{eV}$ for TMP-d9. The cone voltage of mass spectrometer was set to $30 \mathrm{~V}$, and resolution voltage was set to $15 \mathrm{~V}$. Other parameters were set to the factory standard, and the data were acquired and processed using MassLynx software (Waters, Milford, MA, USA).

\section{Results and discussion}

\subsection{Optimization of the DART-MS/MS}

The DART ion source parameters-including the temperature of ion source, the speed of sample passing through the ion source, and the necessity of an oil-free pump connected to the VAPUR interface-were optimized to obtain the best performance. The DART ionization efficiency was temperature-dependent. The temperature of helium affects the desorption rate of the analytes from the sampling stick surface [24]. At elevated temperatures, the helium may cause thermal decomposition of the target molecules and desorption of the noisy matrices, resulting in lower signalto-noise $(\mathrm{S} / \mathrm{N})$ levels $[21,25]$. The moving speed of sample sticks determines the contact time of the heated helium and the sample. The thermal decomposition of analytes and matrices may be inhibited at lower speeds. At higher speeds, the contact time was reduced, resulting in an insufficient desorption of the analytes and thus decreased sensitivity [20]. The use of an oil-free pump for the VAPUR interface can remove the matrices, water cluster ions, and excessive helium to suppress the matrix noise and avoid breaking down the mass spectrometer vacuum balance [22]; however, it may simultaneously cause the loss of analyte ions due to the perpendicularly split flow of the ion streams. 


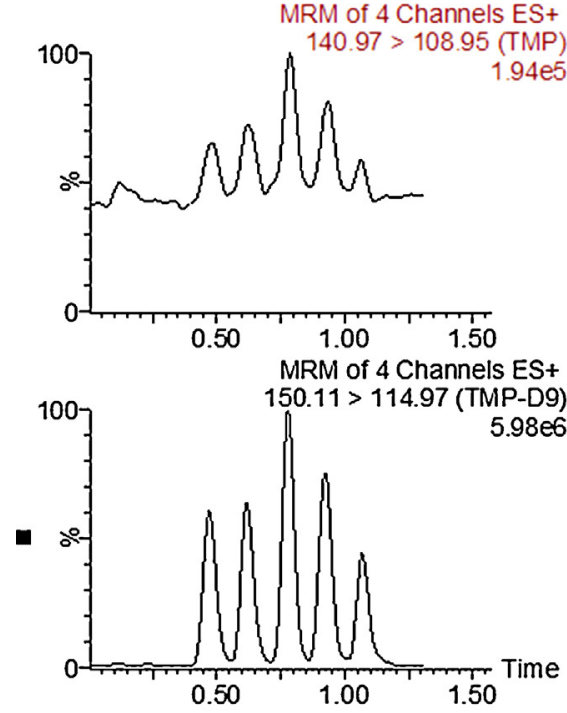

(a)

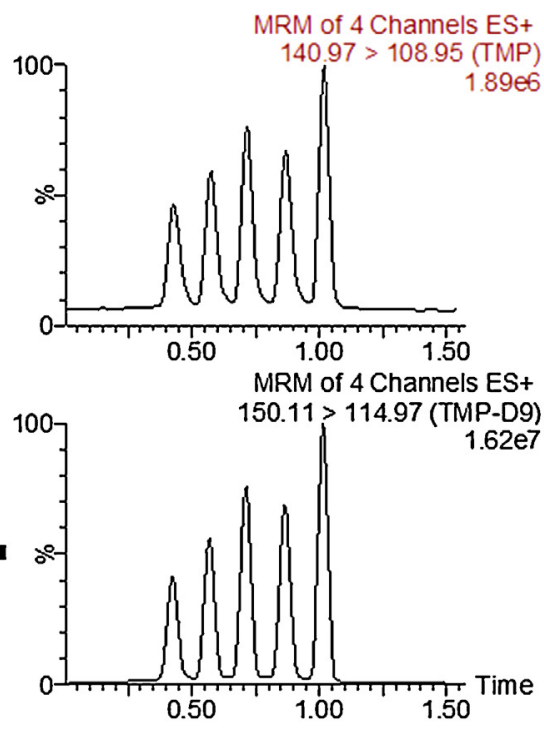

(b)

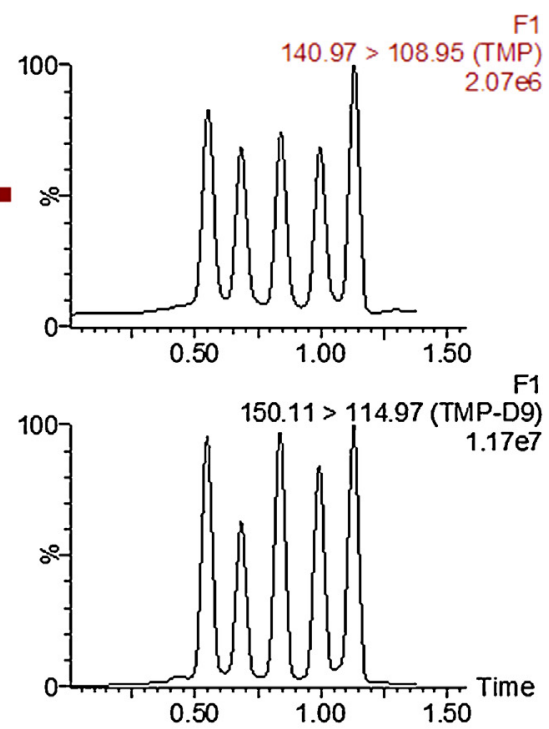

(c)

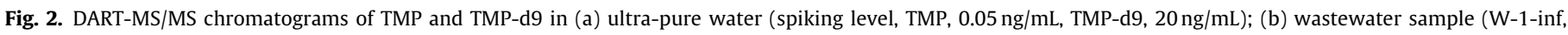
TMP-d9, $20 \mathrm{ng} / \mathrm{mL}$ ); and (c) spiked wastewater sample (W-1-inf, spiking level, TMP, $2 \mathrm{ng} / \mathrm{mL}, \mathrm{TMP}-\mathrm{d} 9,20 \mathrm{ng} / \mathrm{mL}$ ).

Therefore, the ion source temperature ranging from $200^{\circ} \mathrm{C}$ to $500^{\circ} \mathrm{C}$, the moving speed of sampling sticks ranging from $0.5 \mathrm{~mm} / \mathrm{s}$ to $2.0 \mathrm{~mm} / \mathrm{s}$, and the change of signal when switching the oilfree pump were examined. In this study, $450^{\circ} \mathrm{C}$ and $1.0 \mathrm{~mm} / \mathrm{s}$ was chosen for ionization temperature and sampling sticks' moving speed. Due to the higher signal of TMP and the vacuum pressure of mass spectrometer was not broken down, the oil-free pump was switched off throughout the whole experiments.

\subsection{Validation of the method}

In order to evaluate the practical application of the proposed method, the critical validation parameters such as linearity, limit of detection (LOD), limit of quantification (LOQ), recovery, reproducibility (expressed as relative standard deviation (RSD, \%)), and matrix effect were studied.

Linearity was conducted using ten standard solution $(0.05-100 \mathrm{ng} / \mathrm{mL})$ spiked in ultra-pure water. Five replicates measurements were carried out for each level. Internal standard calibration curve of TMP was obtained by performing a linear regression analysis of the peak area ratio of TMP to TMP- $d_{9}$ versus concentration. The result confirmed a satisfactory linearity between $0.05-100 \mathrm{ng} / \mathrm{mL}$ with correlation coefficients greater than 0.998 .

The LOQ was obtained by decreasing the spiked concentration of TMP in ultra-pure water until $S / N \geq 10$. The LOD was determined as the concentration with $S / N=3$. The LOD and LOQ were 15 and $50 \mathrm{pg} / \mathrm{mL}$ (Fig. 2), respectively. The LOQs of river water and wastewater could not be measured because TMP detected in all water samples. The LOQs of real water samples were calculated based on the signal intensity and noise level near the peak $(S / N \geq 10)$ and were identical to the LOQ of ultra-pure water.

The recovery, reproducibility, and matrix effect of TMP were evaluated at 2 spiked levels with 5 replicates (Table 1 ). The matrix effect was calculated based on the following equation: matrix effect $(\%)=\left(1-R_{\mathrm{m}} / R_{0}\right) \times 100 \%$, where $R_{\mathrm{m}}$ is ratio of peak area of background-subtracted fortified sample and $R_{0}$ is the ratio of peak area of the pure standard at the same concentration. The recovery ranged from 88.0 to $107.6 \%$ and the reproducibility varied from 4.6 to $12.2 \%$ were observed. Since the water samples determined without extraction and condensation, the matrix effect from real water was limited $(\leq 20 \%)$ and can be corrected with isotope-labeled internal standard (ISTD) method.

Furthermore, DART SVP showed excellent ionization ability toward aryl and alkyl phosphates, but weak ionization ability for chlorinated-alkyl phosphates under the condition optimized for TMP (Fig. 3). For higher signal intensities of other OPEs, parameters of DART-MS/MS should be optimized individually. Due to the poor reproducibility of DART SVP, for the OPEs which ISTD still not available only qualitative analysis can be carried on.

\subsection{Presence of TMP in real water samples}

Currently, concentrations for most OPEs, except TMP, have been determined in various types of wastewater $[1,26]$. However, the concentration of TMP in these samples has not been quantitatively analyzed. Using the method developed in this study, the

Table 1

TMP measurements, spiked recovery, and matrix effect of real water samples by DART-MS/MS ( $m e a n \pm S D, n=5$ ).

\begin{tabular}{|c|c|c|c|c|c|}
\hline Wastewater sample & Sample measured $(\mathrm{ng} / \mathrm{mL})$ & Spiked (ng/mL) & Spiked measured (ng/mL) & Recovery (\%) & Matrix effect (\%) \\
\hline \multirow[t]{2}{*}{ River water } & $5.51 \pm 0.44$ & 5 & $10.84 \pm 0.82$ & 106.6 & -2.1 \\
\hline & & 10 & $15.18 \pm 1.43$ & 96.7 & 5.4 \\
\hline \multirow[t]{2}{*}{ W-1-inf } & $2.38 \pm 0.15$ & 1 & $3.26 \pm 0.40$ & 88.0 & 20.2 \\
\hline & & 3 & $5.52 \pm 0.44$ & 104.7 & 2.4 \\
\hline \multirow[t]{2}{*}{ W-1-eff } & $3.47 \pm 0.14$ & 2 & $5.27 \pm 0.36$ & 90.0 & 18.8 \\
\hline & & 5 & $8.02 \pm 0.63$ & 91.0 & 12.8 \\
\hline \multirow[t]{2}{*}{ W-2-inf } & $10.84 \pm 0.27$ & 20 & $32.37 \pm 1.49$ & 107.6 & -6.5 \\
\hline & & 50 & $59.14 \pm 6.57$ & 96.6 & 3.8 \\
\hline \multirow[t]{2}{*}{ W-2-eff } & $16.13 \pm 1.3$ & 20 & $34.26 \pm 3.22$ & 90.7 & 10.3 \\
\hline & & 50 & $68.35 \pm 5.36$ & 104.4 & -4.0 \\
\hline
\end{tabular}



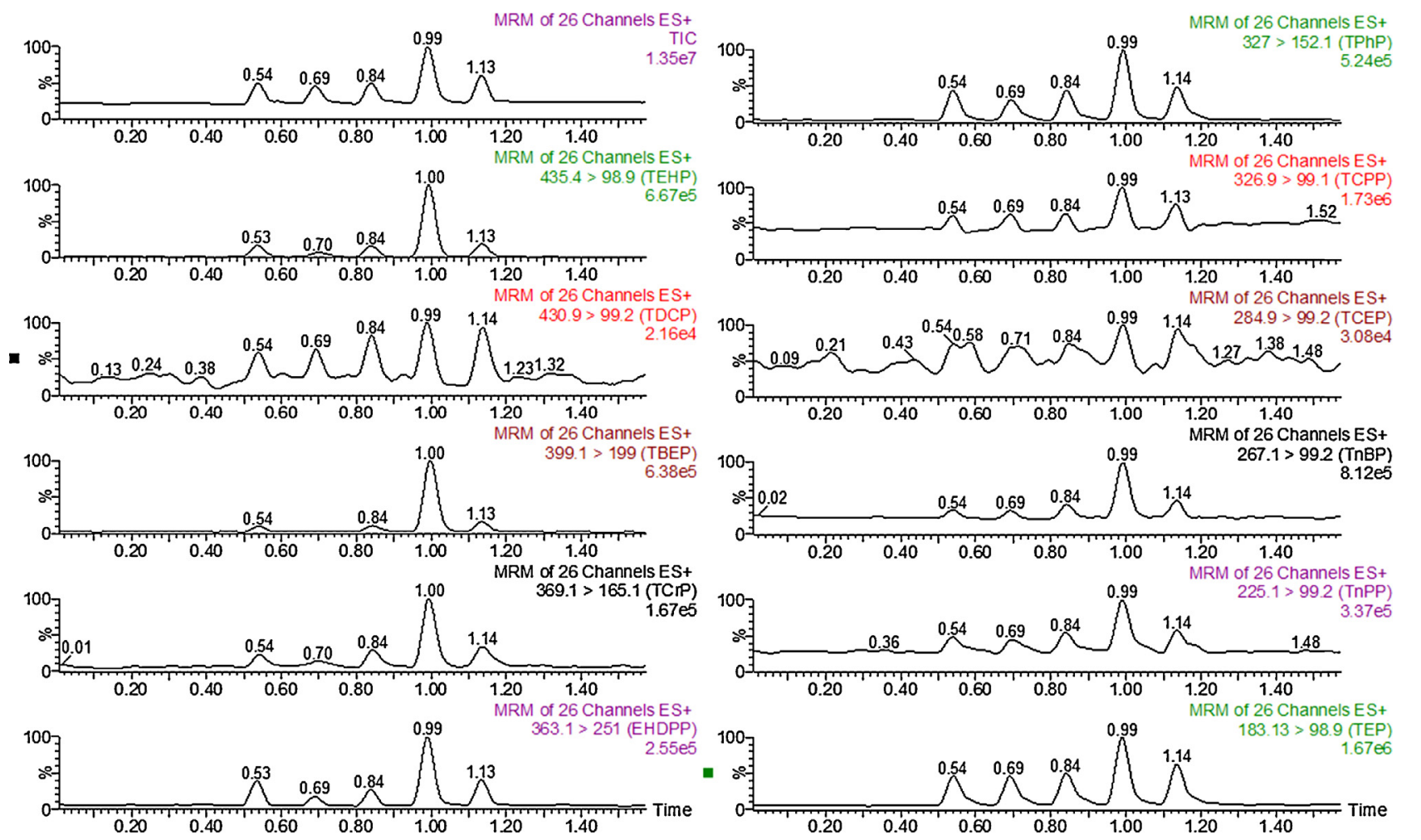

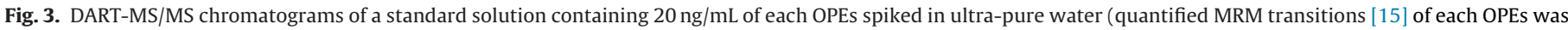
given).

concentration of TMP in real water samples was determined. As shown in Table 1, TMP was detected at concentrations of $2.38 \pm 0.15 \mathrm{ng} / \mathrm{mL}$ and $10.84 \pm 0.27 \mathrm{ng} / \mathrm{mL}$ in the influent water of $\mathrm{W}-1$ and $\mathrm{W}-2,3.47 \pm 0.14 \mathrm{ng} / \mathrm{mL}$ and $16.13 \pm 1.3 \mathrm{ng} / \mathrm{mL}$ in the effluent water of $\mathrm{W}-1$ and $\mathrm{W}-2$. The concentration of TMP was $5.51 \pm 0.44 \mathrm{ng} / \mathrm{mL}$ in the river water. This result indicated that TMP has already existed in environmental water and persistent in the municipal wastewater treatment process. The concentrations of TMP varied depending on the sampling site. These water samples were then spiked with standard TMP solutions to obtain the recoveries, which indicate a recovery range of $88.0-107.6 \%$.

\section{Conclusion}

The present study demonstrates that DART-MS/MS can directly and rapidly detect highly polar TMP in water. The TMP concentration can be accurately quantified through using an ISTD method. Each parameter of the DART ion source can be individually optimized quickly. The method exhibits good linearity $(R>0.998)$ in the range of $0.05-100 \mathrm{ng} / \mathrm{mL}$, with a LOQ of $50 \mathrm{pg} / \mathrm{mL}$ TMP in water. The TMP was accurately detected in real water samples sampling from two WWTP and a river. An excellent reproducibility and recovery was achieved from the spiked water samples. The matrix effect has been corrected with ISTD method. Further studies will focus on the measurements of wastewater samples surrounding Beijing city using the as-developed methodology; the results will be presented elsewhere.

\section{Acknowledgements}

The authors gratefully acknowledge the financial support from National Natural Science Foundation of China for Young Scholars (Grant No. 31301474), National Key Technology R\&D Program (Grant No. 2012BAK17B01) and Beijing Municipal Senior Technical Training Plan in the Health System, and ASPEC Technologies for loaning the DART SVP system. Supports from Xiaokun Duan from ASPEC Technologies, Ping Li and Hui Xu from Lumier Technologies for sample analysis were gratefully appreciated.

\section{References}

[1] T. Reemtsma, J. Benito Quintana, R. Rodil, M. Garcia-Lopez, I. Rodriguez, Trends Analyt. Chem. 27 (2008) 727.

[2] A. Bacaloni, F. Cucci, C. Guarino, M. Nazzari, R. Samperi, A. Lagana, Environ. Sci. Technol. 42 (2008) 1898

[3] United Nations Environment Programme, Trimethyl Phosphate, 1994, http://www.inchem.org/documents/sids/sids/512561.pdf.

[4] Y. Paukku, A. Michalkova, J. Leszczynski, Struct. Chem. 19 (2008) 307.

[5] S.J. Chen, Y.J. Ma, J. Wang, D. Chen, X.J. Luo, B.X. Mai, Environ. Sci. Technol. 43 (2009) 4200.

[6] E.A. Kozlova, A.V. Vorontsov, Int. J. Hydrogen Energy 35 (2010) 7337.

[7] C. Ruan, H. Huang, M.T. Rodgers, J. Am. Soc. Mass Spectrom. 19 (2008) 305.

[8] E.M. Bomhard, G.J. Krinke, W.M. Rossberg, T. Skripsky, Fundam. Appl. Toxicol. 40 (1997) 75

[9] C. Yu, Q. Hao, S. Saha, L. Shi, X.Y. Kong, Z.L. Wang, Appl. Phys. Lett. 86 (2005).

[10] A. Marklund, B. Andersson, P. Haglund, Environ. Sci. Technol. 39 (2005) 7423.

[11] H.M. Stapleton, S. Klosterhaus, S. Eagle, J. Fuh, J.D. Meeker, A. Blum, T.F. Webster, Environ. Sci. Technol. 43 (2009) 7490

[12] A. Marklund, B. Andersson, P. Haglund, Environ. Sci. Technol. 39 (2005) 3555.

[13] R. Rodil, J.B. Quintana, T. Reemtsma, Anal. Chem. 77 (2005) 3083.

[14] A. Bacaloni, C. Cavaliere, P. Foglia, M. Nazzari, R. Samperi, A. Lagana, Rapid Commun. Mass Spectrom. 21 (2007) 1123.

[15] X.W. Wang, J.F. Liu, Y.G. Yin, J. Chromatogr. A 1218 (2011) 6705

[16] R.B. Cody, J.A. Laramee, H.D. Durst, Anal. Chem. 77 (2005) 2297.

[17] L.K. Ackerman, G.O. Noonan, T.H. Begley, Food Addit. Contam. Part A Chem. Anal. Control Expo. Risk Assess. 26 (2009) 1611.

[18] R.R. Steiner, R.L. Larson, J. Forensic Sci. 54 (2009) 617

[19] K. Fouyer, O. Lavastre, D. Rondeau, Anal. Chem. 84 (2012) 8642.

[20] A.H. Grange, Rapid Commun. Mass Spectrom. 27 (2013) 305.

[21] L. Wang, P. Zhao, F. Zhang, Y. Li, C. Pan, Rapid Commun. Mass Spectrom. 26 (2012) 1859.

[22] Y. Zhao, M. Lam, D. Wu, R. Mak, Rapid Commun. Mass Spectrom. 22 (2008) 3217.

[23] J.M. Nilles, T.R. Connell, H.D. Durst, Anal. Chem. 81 (2009) 6744.

[24] R.B. Cody, Anal. Chem. 81 (2008) 1101.

[25] E. Crawford, B. Musselman, Anal. Bioanal. Chem. 403 (2012) 2807.

[26] J.B. Quintana, R. Rodil, T. Reemtsma, M. Garcia-Lopez, I. Rodriguez, Trends Analyt. Chem. 27 (2008) 904. 